\title{
Remote Detection Of A Freshwater Pool Off The Sagavanirktok River Delta, Alaska
}

\author{
A. KOVACS ${ }^{1}$ and R. M. MOREY ${ }^{2}$
}

A recent paper by Kovacs (1978) discussed the findings of a study in which an impulse radar sounding system was used to detect water under ice-covered lakes on the North Slope of Alaska. The study revealed that the radar system could be used to determine, from the ice surface or from a helicopter, lake ice thickness, water depth under the ice, and where the ice was in contact with the lake bottom.

In early May 1978, a pool of fresh water was discovered during impulse radar sounding measurements of sea ice thickness near Howe Island on the coast of the Sagavanirktok River Delta, Alaska. Its potential as a source of potable water was investigated and is reported here.

The impulse radar profiling system used consisted of an electronics console, a graphic recorder and an antenna pulled along the ice surface. The system and its operational characteristics have been described by Morey, (1974), Campbell and Orange, (1974) and Kovacs and Morey, (1978).

The freshwater pool was discovered during an ice thickness profile run along a section of the 1977-78 winter ice road. This road began at the East Dock in Prudhoe Bay (Fig. 1) and continued eastwards along the coast to the vicinity of Flaxman Island. From Heald Point at the tip of the peninsula on the east side of Prudhoe Bay the road ran in a southeast direction toward Howe Island. On this road section the ice was generally grounded on the shallow delta sediments, and long sections of road crossed gravel bars and beaches. At one location on the road the ice abruptly thickened and a subbottom was detected in the radar data.

The graphic record obtained in show in Figure 2. This record is a display of the travel time of the radar signal from the ice surface to the ice/soil, ice/water and water/soil interfaces. The water/soil interface reflection would not be present if sea water of normal salinity existed under the ice as the electromagnetic energy radiated by the antenna cannot penetrate sea water because of its high conductivity. Therefore, the water under the ice was either fresh or its salinity was low enough to allow the radar signal to propagate through to the bottom and back.

'U.S. Army Corps of Engineers Cold Regions Research and Engineering Laboratory, Hanover, New Hampshire, 03755

${ }^{2}$ Morey Research Co., B-3 Black Oak Drive, Nashua, New Hampshire, 03060 


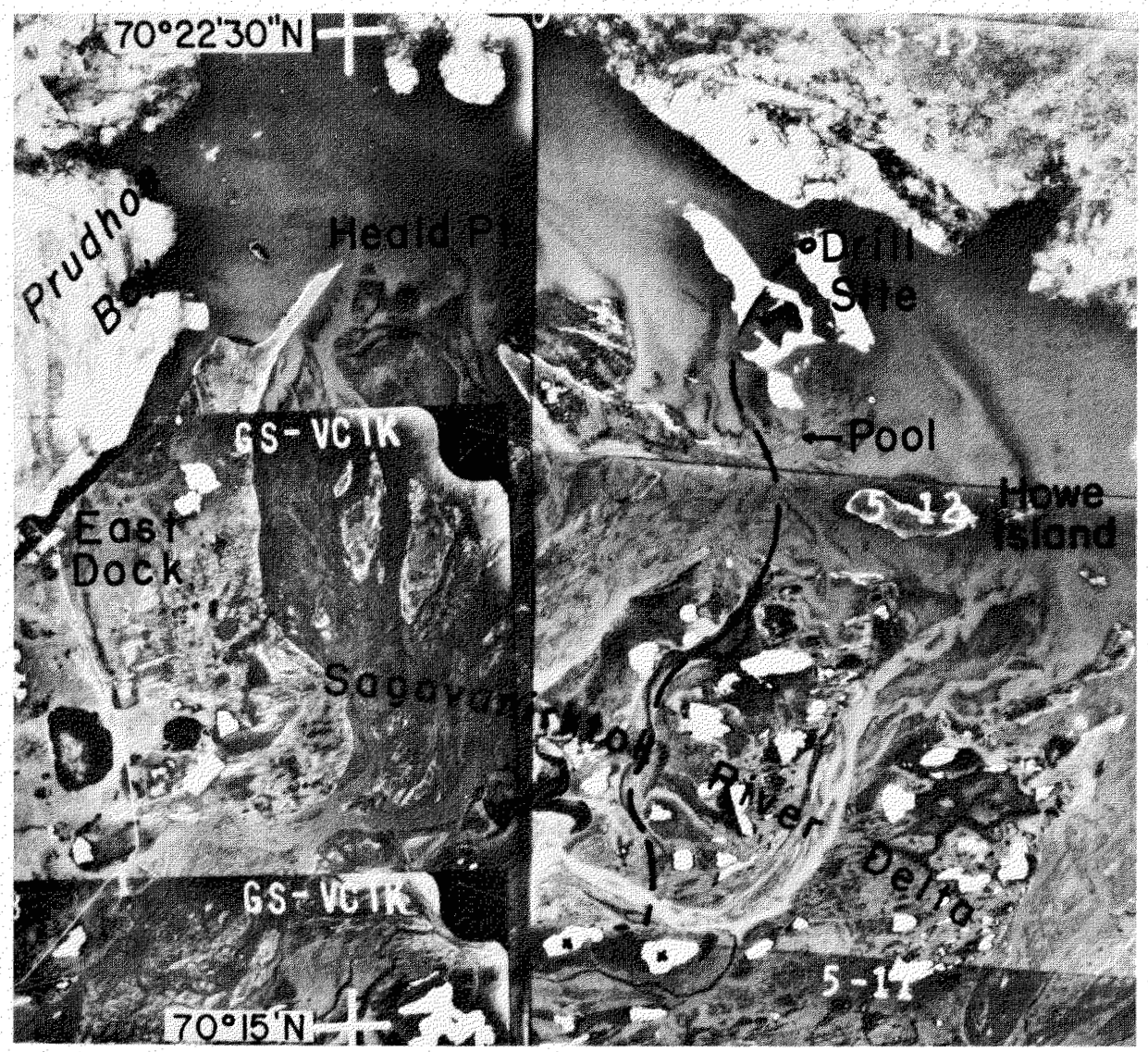

FIG. 1. Photomosaic of the west channel area of the Sagavanirktok River Delta, Alaska.

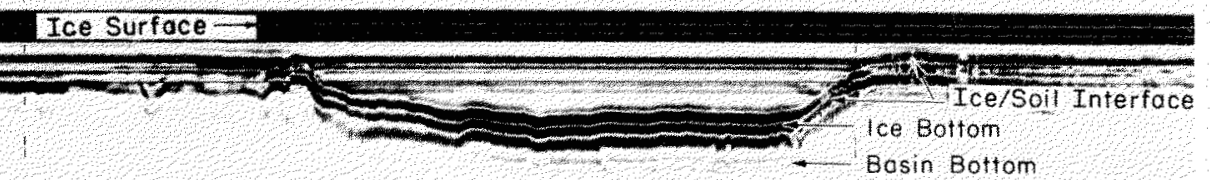

FIG. 2. Graphic record of the impulse radar signal showing the ice road and freshwater pool cross section. The time from the ice surface to the black line at the very bottom of the figure is about $40 \mathrm{~ns}$. 
For certain homogeneous materials, such as fresh water and fresh-water ice, the radar signal velocity $\mathrm{V}_{\mathrm{e}}$ of propagation can be calculated from:

$$
v_{e}=\frac{c}{\sqrt{e_{r}}}
$$

where $\mathrm{c}=$ freespace radar velocity

$\mathrm{e}_{\mathrm{r}}=$ dielectric constant $=81$ for fresh water and $\simeq 3.2$ for freshwater ice.

With the propagation velocity thus determined, the depth $\mathrm{D}$ to an interface can be determined from:

$$
D=V_{e} \frac{t}{2}
$$

where $\mathrm{t}=$ travel time to and from the subsurface interface.

From flight times scaled off the graphic record we determined that the ice thickness ranged between 1.70 and $1.75 \mathrm{~m}$ on the east side of the pool and that the distance from the ice surface to the basin bottom was about $2 \mathrm{~m}$. These measurements were verified by coring through the ice near the east side of the pool. Using a tape measure, we found that the ice thickness was $1.75 \mathrm{~m}$ and the depth to the bottom of the pool was $1.98 \mathrm{~m}$.

An inspection of the core retrieved during drilling indicated that the ice had formed from fresh water. Salinity measurements of the melt-water obtained from sections of the ice core revealed salinities from 0.02 to 0.05 part per thousand $(\%)$. The salinity of the pool water was found to be $0.15 \%$. This salinity is well within public health standards for potable water and is significantly less than the $1.2 \%$ salinity of the tap water at the Deadhorse camp where the authors stayed.

The general location of the pool was determined by odometer distance measurements made on the ice road from the pool to several bluffs and islands along the road. Using these measurements and detailed maps of the area we located the pool on the photomosaic shown in Figure 1. This mosaic shows the west channel area of the Sagavanirktok River Delta during spring runoff on 27 June 1970. The pool area, at the tip of the arrow, is shown to be somewhat circular and its colour indicates that it is filled with silty water.

Figure 1 also shows the location of a man-made gravel island from which an exploratory oil well was drilled during the winter of 1977-78. The dashed line represents the long haul route used by Rolligons to transport fresh water from the two lakes, marked with an $\mathrm{X}$, at the south end of the route to the island drill site. The cost of transporting the water was about three hundred and fifty thousand dollars. Had the drilling rig been supplied from the freshwater pool, less expensive truck transport could have been used over the existing ice roads.

We measured the effective width of the pool to be $\sim 200 \mathrm{~m}$. The aerial photo of the pool shows that it was nearly circular. Therefore, the pool had a surface area of about $31,000 \mathrm{~m}^{2}$. If we assume that there was an effective water depth 
of $1 \mathrm{~m}$ during the drilling operation, then about $31,000 \mathrm{~m}^{3}$ ( 8.2 million gallons) of water would have been easily available. Even half this volume would have been enough to support the drilling operation.

This field study has shown how an impulse radar ice profiling survey can be used to survey for fresh water in isolated pools under the ice cover of arctic river deltas. It complements the earlier field results of Kovacs (1978) who used impulse radar to detect free water under lake ice on the North Slope of Alaska.

\section{REFERENCES}

CAMPBELL, K. J. and ORANGE, A. S. 1974. A continuous profile of sea ice and freshwater ice thickness by impulse radar. Polar Record, 17 (106), p. 30-42.

KOVACS, A. and MOREY, R. M. 1978. Radar anisotropy of sea ice due to preferred azimuthal orientation of the horizontal c-axis of ice crystals. Journal of Geophysical Research, 83, (C12). KovaCS, A. 1978. Remote detection of water under ice-covered lakes on the North Slope of Alaska. Arctic, 31(4) p. 448-458.

MOREY, R. M. 1974. Continuous subsurface profiling by impulse radar. Proceedings of Engineering Foundation Conference on "Subsurface Exploration for Underground Excavation and Heavy Construction," American Society of Civil Engineering, N.Y. 